\title{
On the dynamics in chemical vapor deposition of InN
}

Cite as: J. Appl. Phys. 130, 135302 (2021); https://doi.org/10.1063/5.0061926

Submitted: 30 June 2021 • Accepted: 14 September 2021 • Published Online: 04 October 2021

(D) Chih-Wei Hsu, (D) Petro Deminskyi, (D) Anton Persson, et al.

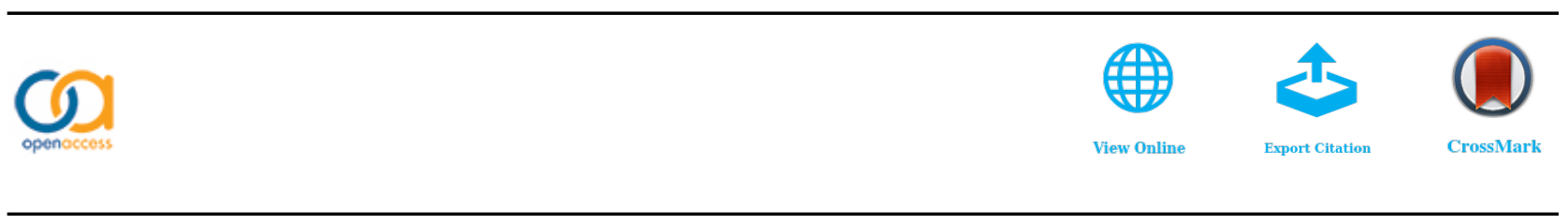

\section{ARTICLES YOU MAY BE INTERESTED IN}

Electrodeposition of $\mathrm{Cu}(111)$ onto a $\mathrm{Ru}(0001)$ seed layer for epitaxial $\mathrm{Cu}$ interconnects Journal of Applied Physics 130, 135301 (2021); https://doi.org/10.1063/5.0063418

Influence of oxygen adsorption from atmosphere on surface tension of liquid silicon Journal of Applied Physics 130, 135101 (2021); https://doi.org/10.1063/5.0062062

Excellent surface passivation of germanium by a-Si:H/ $/ \mathrm{Al}_{2} \mathrm{O}_{3}$ stacks

Journal of Applied Physics 130, 135303 (2021); https://doi.org/10.1063/5.0064808

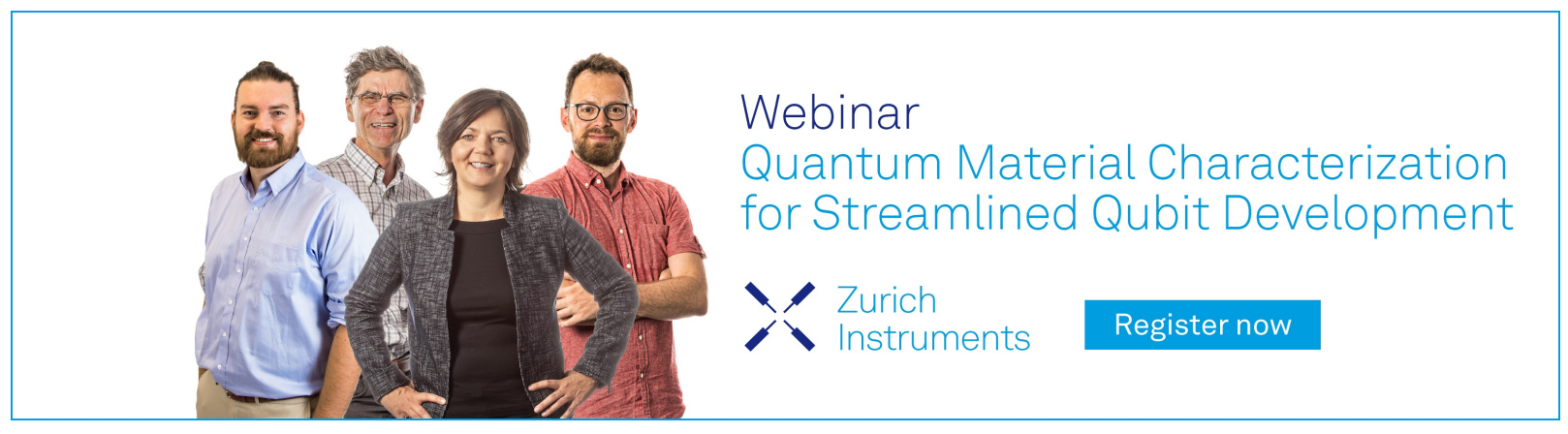




\title{
On the dynamics in chemical vapor deposition of InN
}

\author{
Cite as: J. Appl. Phys. 130, 135302 (2021); doi: $10.1063 / 5.0061926$ \\ Submitted: 30 June 2021 - Accepted: 14 September 2021 . \\ Published Online: 4 October 2021
}

Chih-Wei Hsu, ${ }^{7}$ (D) Petro Deminskyi, ${ }^{1}$ (D) Anton Persson, ${ }^{2}$ (D) Matts Karlsson, ${ }^{2}$ (D) and Henrik Pedersen ${ }^{1, a)}$ (iD

\author{
AFFILIATIONS \\ ${ }^{1}$ Department of Physics, Chemistry, and Biology, Linköping University, SE-58183 Linköping, Sweden \\ ${ }^{2}$ Department of Management and Engineering, Linköping University, SE-58183 Linköping, Sweden
}

a)Author to whom correspondence should be addressed: henrik.pedersen@liu.se

\begin{abstract}
Epitaxial nanometer-thin indium nitride ( $\mathrm{InN}$ ) films are considered promising active layers in various device applications but remain challenging to deposit. We compare the morphological evolution and characterizations of InN films with various growth conditions in chemical vapor deposition (CVD) by both a plasma atomic layer deposition (ALD) approach and a conventional metalorganic CVD approach. Our results show that a time-resolved precursor supply is highly beneficial for deposition of smooth and continuous InN nanometer-thin films. The time for purging the reactor between the precursor pulses and low deposition temperature are key factors to achieve homogeneous InN. The gas exchange dynamics of the reactor is further studied using computational fluid dynamics. According to our study, $320^{\circ} \mathrm{C}$ is found to be the upper temperature where the dynamics of the deposition chemistry can be controlled to involve only surface reactions with surface species. The results highlight the promising role of the ALD technique in realizing electronic devices based on nanometer-thin InN layers.
\end{abstract}

(C) 2021 Author(s). All article content, except where otherwise noted, is licensed under a Creative Commons Attribution (CC BY) license (http://creativecommons.org/licenses/by/4.0/). https://doi.org/10.1063/5.0061926

\section{INTRODUCTION}

III-nitrides (AlN, GaN, and InN) and their alloys are prominent semiconductor materials. AlN and $\mathrm{GaN}$ are highly important for optoelectronic applications and form the backbone in modern light emitting diode technology. The revised bandgap of $\mathrm{InN}$ to $0.7 \mathrm{eV}^{1}$ and its high-electron mobility ${ }^{2,3}$ open up new opportunities, such as IR emitters, sensors, ${ }^{4}$ solar cells, ${ }^{5}$ thin-film transistors, ${ }^{6}$ and high-electron mobility transistors. ${ }^{7}$ As all such applications are based on heterostructures with homogeneous coverage of nanoscale active layers, highly controlled InN epitaxy is paramount to realize any application.

The growth of InN is problematic due to its low thermal stability; InN decomposes to In metal and nitrogen gas at about $550{ }^{\circ} \mathrm{C} .{ }^{8}$ This has also been manifested by its high equilibrium pressure with nitrogen which has led to attempts at depositing $\mathrm{InN}$ at very high nitrogen pressures. ${ }^{9-11}$ Due to slow decomposition kinetics of ammonia $\left(\mathrm{NH}_{3}\right)$, ${ }^{12}$ the most common nitrogen precursor in chemical vapor deposition (CVD), N/In ratios in the order of $>10^{4}$ have often been used in CVD of InN. ${ }^{13}$ Alternative N-precursors, such as dimethylhydrazine and tertiarybuthylhydrazine, have been shown ineffective for the growth of InN. ${ }^{14}$ To allow more reactive $\mathrm{N}$ species, plasma-assisted approaches have been adapted in various growth techniques, such as molecule beam epitaxy, ${ }^{15-17}$ sputtering, ${ }^{18}$ and metalorganic $\mathrm{CVD}^{19}$ for the growth of InN.

We have previously hypothesized that steering the deposition chemistry fully to the surface could be an alternative route for low temperature CVD of InN as it could circumvent the problem of the slow kinetics in the gas phase decomposition of $\mathrm{NH}_{3}$. A CVD approach fully relying on surface chemistry is atomic layer deposition (ALD), which uses a sequential supply of the precursor gases to make the deposition chemistry surface controlled. ${ }^{20}$ ALD of crystalline InN films has been demonstrated using trimethyl indium (TMI) and either nitrogen plasma ${ }^{21,22}$ or $\mathrm{NH}_{3}$ plasma. ${ }^{23}$ In addition, complex precursors with chelating ligands with In-N bonds have also been employed to prepare polycrystalline ${ }^{24}$ or epitaxial $\mathrm{InN}^{25}$ with $\mathrm{NH}_{3}$ plasma. Recently, we demonstrated that epitaxial and homogeneous wurtzite $\mathrm{InN}$ films on $4 \mathrm{H}-\mathrm{SiC}$ substrate with a thickness down to $5 \mathrm{~nm}$ can be grown by using plasma ALD at $320^{\circ} \mathrm{C},{ }^{26}$ which has never been reported by other growth techniques. ALD thus seems to be more promising than other techniques 
to achieve homogeneous, epitaxial, nanometer-thin InN films. However, the understanding of why ALD holds such advantage over conventional thermal CVD is not properly addressed.

Here, we present an experimental study in which we compare the outcomes from ALD and conventional CVD process using TMI and $\mathrm{NH}_{3}$ for both approaches. Our results demonstrate that nanometer-thin homogenous InN can only be deposited by a timeresolved CVD approach. The morphology of InN is heavily controlled by the purge time between the precursor pulses and the surface temperature. The transient gas exchange of the reactor is further studied using computational fluid dynamics (CFD). The deposition chemistry dynamics is suggested as a critical factor for the deposition of nanometer-thin InN layer which has the potential for device applications.

\section{METHODS}

\section{A. InN deposition by ALD}

A Picosun R-200 ALD system was employed to grow InN films using trimethyl indium, $\operatorname{In}\left(\mathrm{CH}_{3}\right)_{3}$ (TMI), and plasma discharged $\mathrm{NH}_{3} / \mathrm{Ar}$ gas mixture. A detailed process development can be found in our earlier work. ${ }^{23}$ In this work, $4 \mathrm{H}-\mathrm{SiC}$ (0001) was used as the substrate, which allows epitaxial growth of $\mathrm{InN} .^{26}$ The samples are loaded in the system without a load lock chamber. The plasma is generated within a quartz tube surrounded by a cylindrical rf coil. The heated substrate holder is located approximately $70 \mathrm{~cm}$ below the plasma source. $\mathrm{N}_{2}(99.999 \%$ and further purified by a getter filter) was used as purge gas in the system and as carrier gas for the TMI (Pegasus Chemicals, Alpha grade). As previously described, a fill-empty pulsing scheme was used to get a sufficient flow of TMI in to the deposition chamber. ${ }^{23}$ The $\mathrm{NH}_{3}$ plasma was ignited using a mixture of $50 \mathrm{SCCM} \mathrm{NH} 3(99.9990 \%$ and further dried with a getter filter) and 100 SCCM Ar (99.9997\% and further purified with a getter filter). The applied rf power for the $\mathrm{NH}_{3}$ plasma is $2800 \mathrm{~W}$. The rf power used in our work is much higher than the typical values (few hundred Watts) found in papers by other research groups. The power used stems from the design of our Picosun plasma ALD reactor where the ICP tube is located approximately $70 \mathrm{~cm}$ above the substrate holder in a relatively large volume reactor. Prior to the deposition of InN, the substrates were subjected to a 2 -min plasma exposure $(2800 \mathrm{~W})$ with a 100 SCCM Ar +50 SCCM N 2 plasma gas mixture, followed by 550 InN ALD cycle after a $10 \mathrm{~s} \mathrm{~N}_{2}$ purge. The InN ALD cycle comprises $4 \mathrm{~s}$ TMI pulse, $10 \mathrm{~s} \mathrm{~N}_{2}$ purge, $12 \mathrm{~s}$ plasma exposure using $50 \mathrm{SCCM} \mathrm{NH} \mathrm{N}_{3}+100 \mathrm{SCCM}$ Ar and $2800 \mathrm{~W}$, and $6 \mathrm{~s} \mathrm{~N}_{2}$ purge. The deposition temperatures were between 250 and $450{ }^{\circ} \mathrm{C}$ while the pressure was kept at 6 mbar for all growth runs. A small pressure fluctuation jumping from 6 to 10 mbar was observed while the TMI pulse is being introduced into the chamber. The pressure fluctuation was removed automatically within $2 \mathrm{~s}$.

In some experiments which were done to demonstrate the importance of controlled surface reaction, the purge time between TMI and $\mathrm{NH}_{3}$ plasma pulses was varied between 0.1 and $8 \mathrm{~s}$ with growth temperature of $320^{\circ} \mathrm{C}$. To facilitate the comparison on the surface morphology of initial deposition stage, 150 ALD cycles (with a nominal thickness of $6 \mathrm{~nm}$ at $320^{\circ} \mathrm{C}$ and $10 \mathrm{~s}$ purge time) were performed for each condition.
For the sake of simplicity, we will refer to all samples deposited in this manner as samples deposited by ALD, even if the process conditions are such that a self-limiting behavior is not observed.

\section{B. InN deposition by continuous CVD}

An Aixtron/Epigress horizontal hot-wall MOCVD reactor was used to grow InN for comparison. TMI (SAFC Hitech, Epi-pure grade) and $\mathrm{NH}_{3}$ (99.9990\% and further dried with a getter filter) were used as the precursors, and $4 \mathrm{H}-\mathrm{SiC}(0001)$ was used as the substrate. The deposition was performed with $\mathrm{N}_{2}$ (99.999\% and further purified by a getter filter) as process gas between 320 and $450{ }^{\circ} \mathrm{C}$ with continuous supply of both precursors for $30 \mathrm{~min}$. The process pressure was kept at 50 mbar. The gas flows are $15 \mathrm{slm} \mathrm{N}_{2}$, $2 \mathrm{slm} \mathrm{NH}_{3}$, and $0.2 \mathrm{SCCM} \operatorname{In}\left(\mathrm{CH}_{3}\right)_{3}$, giving rise to a N/In ratio of 10000 . The growth time of $30 \mathrm{~min}$ combined with the total flow of TMI was chosen so that the same amount of TMI molecules was introduced into both the ALD and CVD experiments.

\section{Film characterization}

The surface morphologies of the InN samples were studied by high-resolution LEO 1550 Gemini field emission scanning electron microscope (SEM). The crystalline quality, thickness, and the macro-scale roughness were characterized by using $\mathrm{x}$-ray diffraction (XRD) (PANalytical X'Pert Pro with a Cu-anode x-ray tube). Grazing-incidence XRD (GIXRD) and symmetric $2 \theta-\omega$ and $\omega$-scans were used to study the crystalline quality. The film thickness was determined by analyzing the x-ray reflectivity (XRR) results. The XRR data were fitted by software PANalytical X'Pert reflectivity using a two-layer model of the InN film and the substrate (InN/substrate).

\section{Gas transport modeling of ALD reactor}

The gas exchange dynamics of the TMI pulse-purge ALD-half cycle at 320 and $450^{\circ} \mathrm{C}$ was modeled using computational fluid dynamics (CFD). The time-dependent concentration of the gaseous species in the TMI precursor pulse in the close vicinity of the substrate was investigated. The reactor geometry was discretized to a grid of $7 \times 10^{6}$ elements. The governing equations of mass, momentum, and energy conservation were numerically solved together with the species transport equation using the finite volume solver Ansys Fluent 2020R2 (ANSYS Inc., Canonsburg, PA, USA). Due to the low vapor pressure of TMI in combination with the vacuum draw bubbler used for precursor supply, ${ }^{23}$ TMI was modeled as a passive concentration diluted in the carrier gas with an ideal, square-wave pulse. No chemical reactions were considered in the residence time model since the chamber volume is large (in the order of $10^{4} \mathrm{~cm}^{3}$ including the plasma cone) and the disk-shaped substrate holder where the flow impinges have a large gas volume directly on top due to the plasma cone [see Fig. 6(b)]. Hence, the bulk of the precursor is expected to pass over the substrate and through the chamber without any reactions and give negligible impact on the flow pattern. The main objective of this modeling is to study the time needed to purge the deposition chamber from TMI before the start of the $\mathrm{NH}_{3}$ pulse to avoid overlap of 
precursors; and due to the idealizations, the model cannot provide quantitative results such as growth rate. Additional computational details are given in the supplementary material.

\section{RESULTS AND DISCUSSION}

Figures 1(a)-1(c) show the surface morphologies of the resulting materials on $\mathrm{SiC}$ grown by both ALD (upper right parts) and CVD (lower left parts) approaches between 320 and $450{ }^{\circ} \mathrm{C}$. For the cases of ALD, weak but homogeneous particle-like features can be seen on the substrate surface at $320^{\circ} \mathrm{C}$ [Fig. 1(a)] and below (not shown). With increasing temperature, the grain size increases, and the surface coverage decreases, leading to a non-continuous film as illustrated in Fig. 1(b). At $450^{\circ} \mathrm{C}$ and above (not shown), micro-size droplets/particles are found dominating the surface [Fig. 1(c)]. For the films from continuous CVD, barely any surface features are seen on the sample deposited at $320^{\circ} \mathrm{C}$ [Fig. 1(a)]. At $400{ }^{\circ} \mathrm{C}$, very low density of nanoparticles can be found on the substrate [Fig. 1(b)]. At $450^{\circ} \mathrm{C}$, separated, hexagonal grains with diameter ranging from a few $\mathrm{nm}$ to $50 \mathrm{~nm}$ can be observed [Fig. 1(c)]. Note that the dimension of the islands (few tens $\mathrm{nm}$ ) deposited by CVD at $450^{\circ} \mathrm{C}$ is much smaller than the droplets $(1-2 \mu \mathrm{m})$ found on the sample deposited by ALD at $450^{\circ} \mathrm{C}$.

XRR has been performed to study the growth rate of all $\mathrm{InN}$ films. However, only samples grown by ALD at $320^{\circ} \mathrm{C}$ revealed clear $\mathrm{x}$-ray intensity fringes induced by the smooth and continuous film. The thickness fringes are barely seen for samples by ALD at $400{ }^{\circ} \mathrm{C}$ and thereafter disappear completely for all other samples (Fig. S1 in the supplementary material). We believe this is a consequence of high surface roughness observed in most of the studied samples as shown in Fig. 1. Meanwhile, the absence of noticeable thickness fringes also indicates that the existence of the buffer layer between InN and the substrate is negligible.

Crystalline, hexagonal InN can be found by XRD in the samples deposited by ALD as seen from the InN (0002) diffraction peak at $31.3^{\circ}$ in Fig. 2(a). The satellite peaks in the vicinity of InN (0002), observed in the samples deposited at $320^{\circ} \mathrm{C}$, are thicknesscorrelated fringes. The presence of thickness fringe can be ascribed to heterojunctions with smooth surface and sharp interface. ${ }^{26}$ Such thickness fringes disappear in $\mathrm{InN}$ grown at higher temperatures due to higher surface roughness. Despite that the roughness increases with increasing temperature, the stacking coherence of the InN crystal was not affected as shown by the $\omega$-scans against the $\operatorname{InN}(0002)$ between 320 and $400{ }^{\circ} \mathrm{C}$. The full-width-halfmaximum of the InN (0002) peak in ALD deposited films being nearly identical to the $\mathrm{SiC}$ substrate in the range of $20-50$ arcsec [Fig. 2(b)]. For samples grown by $\mathrm{ALD}$ at $450{ }^{\circ} \mathrm{C}$, the crystalline quality of InN is notably degraded by showing a broad FWHM of $600 \mathrm{arcsec}$. The additional peaks at $30.58^{\circ}$ and $32.93^{\circ}$ in the $2 \theta-\omega$ scan can be indexed to $\mathrm{In}_{2} \mathrm{O}_{3}$ and metallic In, respectively. In droplets, as observed in Fig. 1(c), have been previously reported during growth of InN under elevated temperatures and In-rich conditions. ${ }^{27}$ Among the samples deposited by CVD, only the sample deposited at $450{ }^{\circ} \mathrm{C}$ shows XRD peaks that can be indexed to InN [Fig. 2(a)]. The FWHM of the InN (0002) in the $\omega$-scan for the sample deposited by CVD is roughly 350 arcsec [Fig. 2(b)], which is significantly wider than for films prepared by ALD at lower
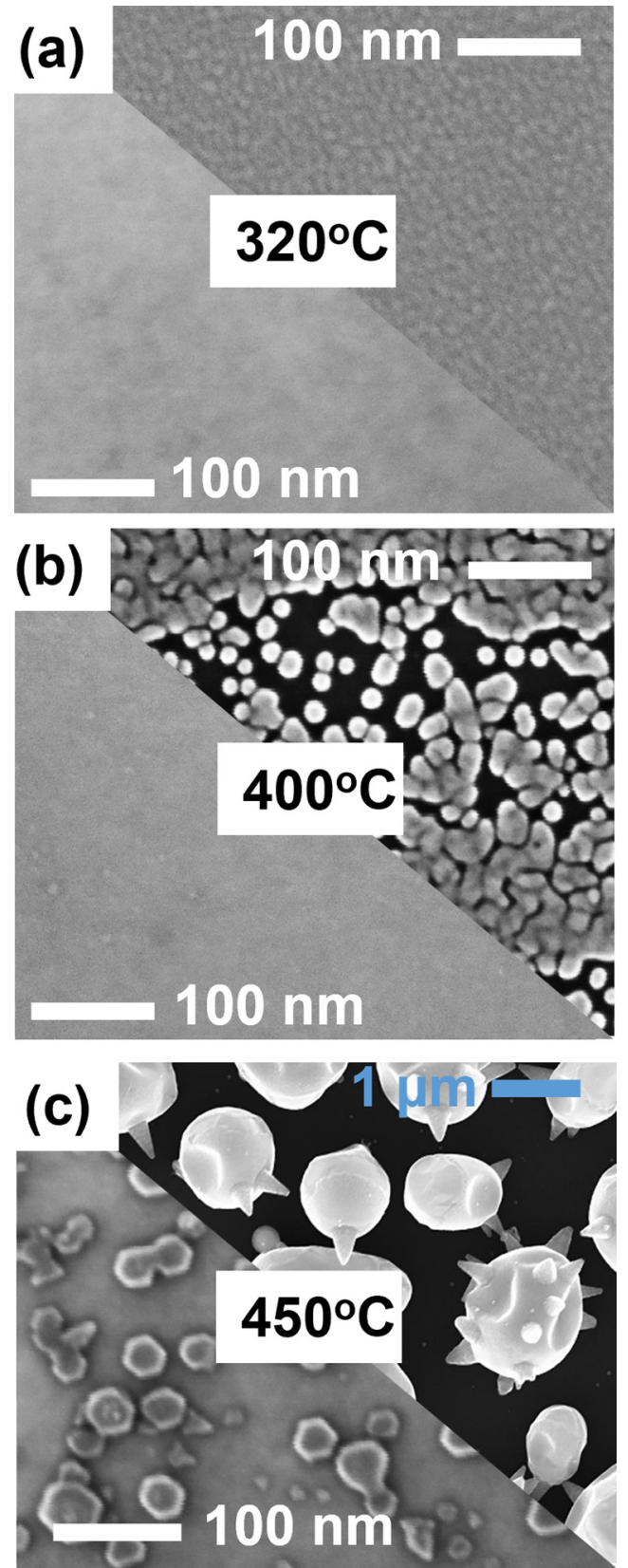

FIG. 1. Top-view SEM images of InN grown on SiC by using both ALD and continuous CVD at different deposition temperatures: (a) 320, (b) 400, and (c) $450^{\circ} \mathrm{C}$. In each figure, the result from ALD is shown in the upper right part while the result from continuous CVD is shown in the bottom left part.

temperatures in this work but is comparable to previously reported CVD films. ${ }^{13}$

In Fig. 2(a), a down shift of the InN (0002) peak for approximately $0.15^{\circ}$ with respected to the strain-free $\operatorname{InN}(0002)$ at $31.3^{\circ}$ 

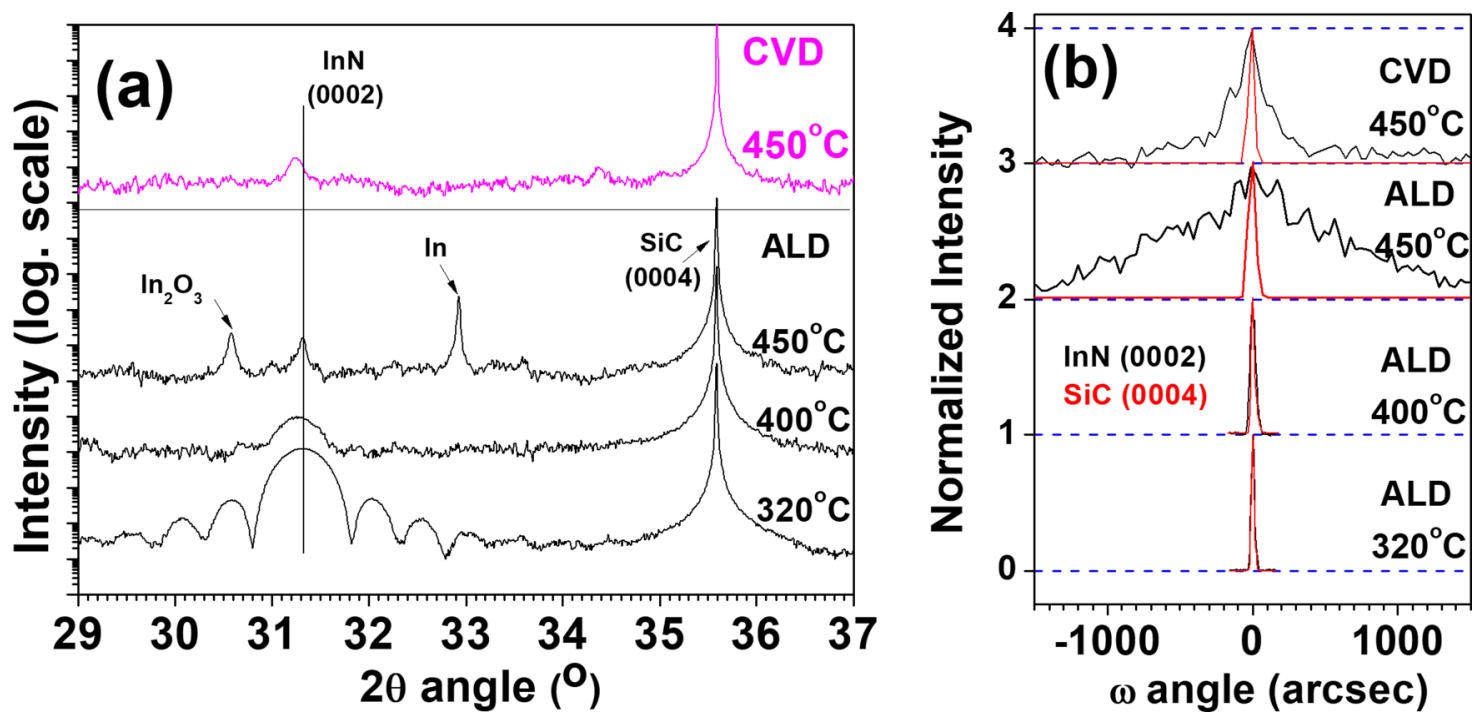

FIG. 2. X-ray diffractograms of (a) symmetric $2 \theta-\omega$ scan of InN films deposited on $4 \mathrm{H}-\mathrm{SiC}$ (0001) by ALD and continuous CVD. The process temperatures of ALD are indicated, respectively, in the plot. The curves are plotted in the log scale and are shifted vertically for visual clarity. (b) $\omega$ scan of InN (0002) and SiC (0004) of samples deposited at different temperatures.

is observed for all samples except the one by $\operatorname{ALD}$ at $320^{\circ} \mathrm{C}$ [Fig. 2(a)]. Such a XRD peak shift is most likely due to strain caused by the lattice mismatch to the substrate and/or defects within the films. According to our earlier study, the InN layer becomes relaxed efficiently via the formation of misfit dislocations. ${ }^{26}$ A strain-free InN can be indexed for samples thicker than $5 \mathrm{~nm}$ by XRD. ${ }^{26}$ Instead of strain from the substrate, we suggest that oxygen could play a significant role for this. Owing to the very oxyphilic nature of In, seen from the standard Gibbs free energy of formation of $-831 \mathrm{~kJ} / \mathrm{mol}$ for $\operatorname{In}_{2} \mathrm{O}_{3}$ and $-105 \mathrm{~kJ} / \mathrm{mol}$ for $\mathrm{InN},{ }^{28}$ any residual $\mathrm{O}$ in the reactor and post-oxidation from air exposure can results in $\mathrm{InO}_{\mathrm{x}} \mathrm{N}_{\mathrm{y}}$ or even $\mathrm{In}_{2} \mathrm{O}_{3}$. Peak down shift with respect to InN (0002) in the XRD symmetric scan has been observed for
$\mathrm{InO}_{\mathrm{x}} \mathrm{N}_{\mathrm{y}}$ before it turns completely into $\mathrm{In}_{2} \mathrm{O}_{3}$, which typically forms the cubic structure that is very different from the wurtzite structure of InN. ${ }^{29}$ According to EDX element mapping (Fig. 3), $\mathrm{In}, \mathrm{N}, \mathrm{O}$, and $\mathrm{Si}$ are uniformly distributed for samples deposited at $320^{\circ} \mathrm{C}$ by ALD [Fig. 3(a)] while an aggregation of oxygen together with In and $\mathrm{N}$ can be observed for samples deposited at $400^{\circ} \mathrm{C}$ by ALD [Fig. 3(b)]. It has been found that the non-c plane surfaces are more favorable for oxygen incorporation in $\mathrm{GaN}^{30}$ Assuming InN behaves similarly as $\mathrm{GaN}$, the scattered small crystal grains seen in the sample deposited at $400^{\circ} \mathrm{C}$ afford a higher surface area leading to enhanced oxygen incorporation and oxidation. We, therefore, suggest that the shift of the XRD peak in Fig. 2(a) is due to the formation of $\mathrm{InO}_{\mathrm{x}} \mathrm{N}_{\mathrm{y}}$ caused by the residual oxygen
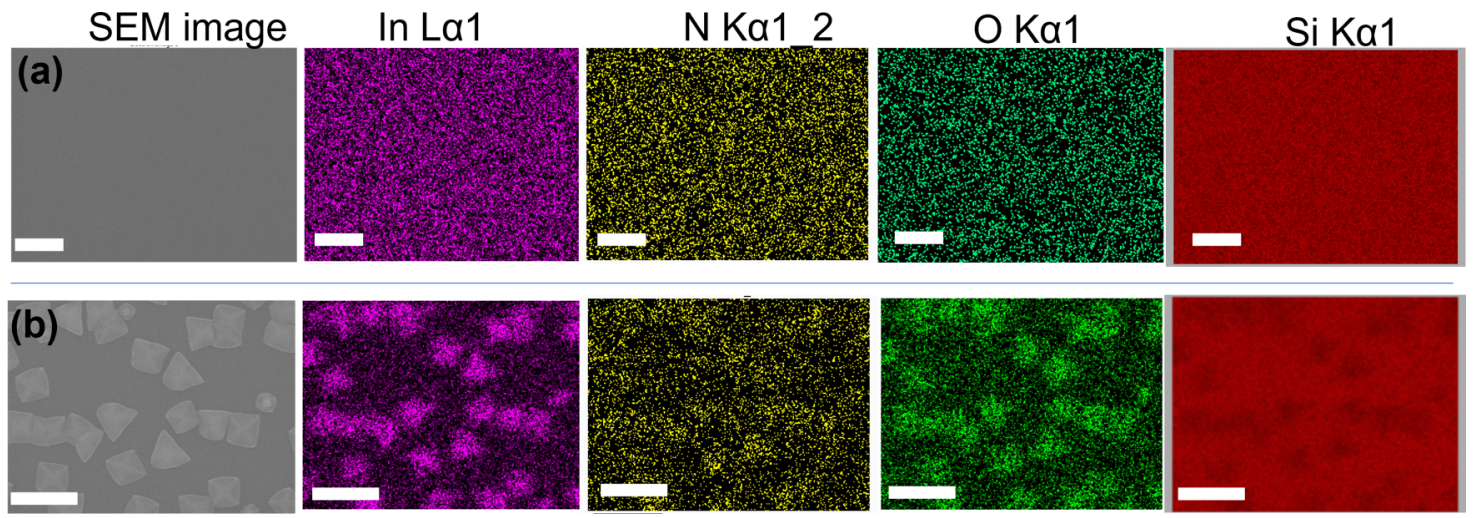

FIG. 3. EDX elemental mapping on samples deposited by ALD at (a) 320 and (b) $400^{\circ} \mathrm{C}$. The corresponding elemental mappings indexed in different colors are shown to the right of respective SEM images. The white scale bars correspond to $1 \mu \mathrm{m}$. 
presented in the reactor during the growth and possibly also postdeposition air exposure.

The results in Figs. 1 and 2 show that the ALD process holds advantages over the conventional continuous CVD for deposition of InN. There are two major differences between the ALD and CVD approaches: the ALD approach uses plasma activation for the ammonia and the time-resolved supply of the precursors. The difference in the film deposition seen in Fig. 1 is likely explained by one or both differences. When a time-resolved precursor supply was used in the CVD reactor, no film was obtained at any temperature. When the plasma was disabled in our ALD reactor and a thermal ALD process for InN was attempted, no sign of InN deposition could be seen even at $450{ }^{\circ} \mathrm{C}$. On the other hand, with plasma activation of the $\mathrm{NH}_{3}$ pulse, $\mathrm{InN}$ can be deposited even at $180^{\circ} \mathrm{C}$ in the ALD reactor, albeit with a reduced deposition rate and crystalline quality. ${ }^{23}$ This demonstrates the importance of the plasma activation of the $\mathrm{NH}_{3}$ pulse. The utilization of plasma, affording more reactive $\mathrm{N}$ species, has been shown to increase the growth rate ${ }^{31}$ as well the crystalline quality of $\mathrm{InN}$ in both $\mathrm{ALD}^{23}$ and CVD systems. ${ }^{32}$ The plasma activation, therefore, seems paramount for the InN deposition at low temperature.

In continuous CVD processes, deposition of $\mathrm{InN}$ requires higher temperatures than in ALD (Figs. 1 and 2). The growth of InN by continuous CVD is suggested to depend on gas-phase reactions initiated from the adducts formed by mixing TMI and $\mathrm{NH}_{3}{ }^{33}$ Interestingly, pulsed flow of TMI into a continuous flow of $\mathrm{NH}_{3}{ }^{34,35}$ and a pulses of TMI and $\mathrm{NH}_{3}$ with slight overlap ${ }^{36}$ have been reported to deposit good quality continuous InN films when the thickness exceeded $75 \mathrm{~nm}$. Separating TMI and $\mathrm{NH}_{3}$ was concluded advantageous for InN deposition in these studies. The separation of TMI and $\mathrm{NH}_{3}$ should reduce the formation of adducts in the gas-phase and change the deposition chemistry. ${ }^{37,38}$ Consequently, we suggest that purge time is an important parameter which modulates reaction mechanism and its dynamics and strongly influences the deposited InN quality.

An ALD process needs to be done at relative low temperature to ensure the stability of the chemisorbed monolayer. Meanwhile, a sufficiently long purge time is also required to eliminate unwanted
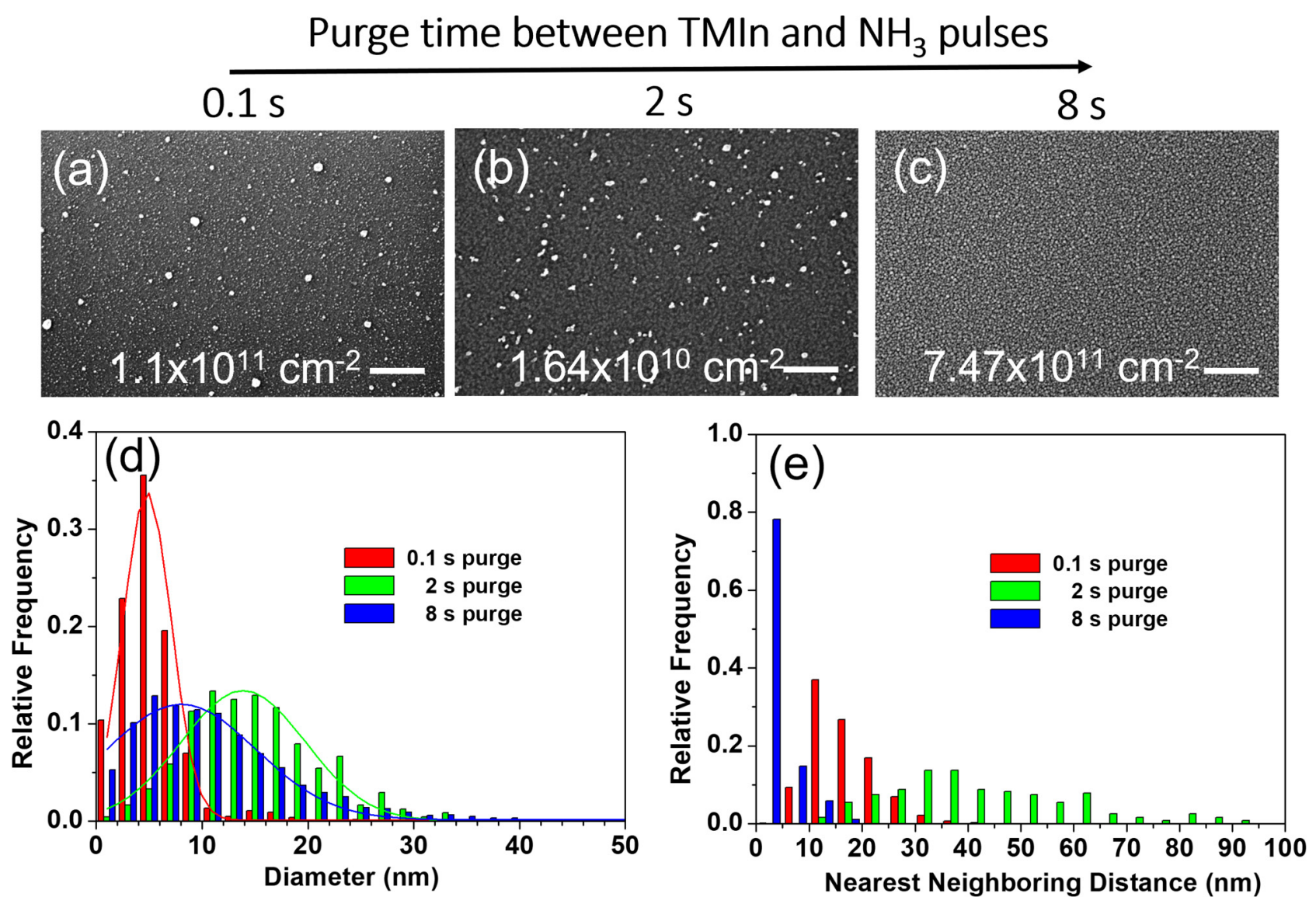

FIG. 4. SEM images of InN grown by ALD using the standard growth conditions with different purge times between $\mathrm{TMI}$ and $\mathrm{NH}_{3}$ pulses at $320^{\circ} \mathrm{C}$. The purge times were (a) 0.1 , (b) 2 , and (c) $8 \mathrm{~s}$. The white scale bars correspond to $200 \mathrm{~nm}$ in all images. The diameter and nearest neighboring distance of the bright particles in (a)-(c) were analyzed by using ImageJ. The particle density for each image is also indicated. The statistical results are presented in histograms (d) and (e). 
chemical reactions of physiosorbed molecules. In fact, our ALD work was done in a temperature range higher than the typical InN ALD window of $150-300^{\circ} \mathrm{C} \cdot .^{21,22,38-41}$ Considering the difference in film deposition observed in Figs. 1 and 2 at different temperatures and the thermal stability of TMI, our ALD of InN is likely to involve several In-species. TMI is considered to be stable up to $300{ }^{\circ} \mathrm{C}$. Between 300 and $325^{\circ} \mathrm{C}$, TMI is reported to decompose fractionally to dimethylindium (DMI) and methyl radicals by homolytic cleavage of one In-C bond. ${ }^{39}$ DMI has also been suggested as a stable surface specie in ALD of InN from TMI. ${ }^{40}$ We, therefore, consider DMI as the main chemisorbed In-species on the surface below $325^{\circ} \mathrm{C}$ and the overall surface reaction remains controllable. The reaction will eventually become uncontrollable by further increasing the temperature.

Excess precursors, reaction by-products, and physiosorbed surface species should be removed and evacuated by purging the ALD system with inert gas, $\mathrm{N}_{2}$, in our experiments. To further study the influence of purge time and in the best possible attempt to mimic continuous CVD in our ALD reactor, we did InN ALD experiments with varied purge time. After the TMI pulse and the subsequent purge, the surface was exposed to $\mathrm{NH}_{3}$ plasma, which nitridized the surface and immobilized all In species. The surface morphologies of InN ALD grown with different purge times are then a reflection of the behavior of the adsorbed In-species on the surface.

When $0.1 \mathrm{~s}$ purge time is used after the TMI pulse in a $320^{\circ} \mathrm{C}$ deposition, a very high density $\left(1.1 \times 10^{11} \mathrm{~cm}^{-2}\right)$ of scattered particles is seen by top-view SEM [Fig. 4(a)]. A longer purge of $2 \mathrm{~s}$ results in a reduced density $\left(1.6 \times 10^{10} \mathrm{~cm}^{-2}\right)$ of averagely larger particles [Fig. 4(b)]. With a long purge time of $8 \mathrm{~s}$, a high-density particle-like feature $\left(7.5 \times 10^{11} \mathrm{~cm}^{-2}\right)$ can be seen uniformly on the surface [Fig. 4(c)]. The particle-like surface feature is likely due to a Stranski-Krastanov growth mode where 3D growth takes over after a critical thickness of approximately $1 \mathrm{~nm} .^{41}$ The particle density, particle size, and inter-particle distance can be used to depict the distribution of adsorbed In-species on the surface, which changes with time, reflecting their mobility. According to our analysis, the average particle size increases from 5 to $16 \mathrm{~nm}$ [Fig. 4(d)] and the inter-particle distance also increases significantly [Fig. 4(e)] by increasing the purge time from 0.1 to $2 \mathrm{~s}$. The increase in diameter of particles and inter-particle distance with longer purge time is an indication that the physiosorbed In-species on the surface are mobile until they are immobilized by the $\mathrm{NH}_{3}$ plasma. According to the work by Muneshwar and Cadien, an ALD precursor pulse results in physiosorbed species and able to diffuse on the surface before being chemisorbed. ${ }^{42}$ With a long purge, all physiosorbed surface species should either chemisorb or desorb from the surface, leaving only chemisorbed In-species for nitridation. The growth per ALD cycle increases with increasing purge time: $0.1 \mathrm{~s}$ purge renders $0.22 \AA$ /cycle, 2 s purge renders $0.31 \AA$ /cycle, and 8 s purge gives $0.41 \AA /$ cycle as shown in Fig. 5 . Such a trend has been previously seen by Muneshwar and Cadien ${ }^{42}$ and suggests that the surface dynamics, producing chemisorbed species, is of very high importance for the film deposition. In addition, $8 \mathrm{~s}$ is adequate for the purge time in our case as the growth rate becomes saturated (Fig. 5). The SEM image shown in Fig. 4(c) reflects the outcome of InN deposition with an adequate purge time to have, presumably,

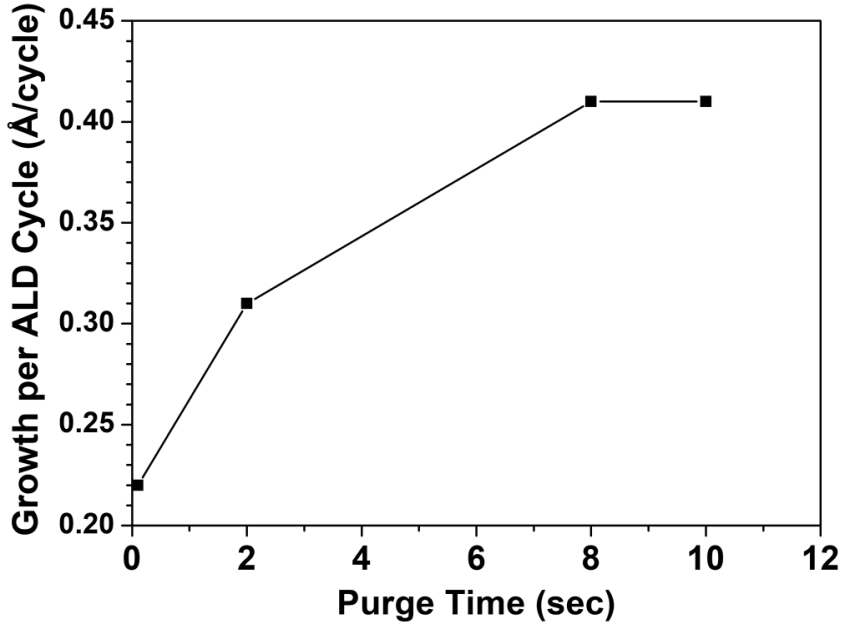

FIG. 5. The growth rate per ALD cycle plotted against different purge times between TMl and $\mathrm{NH}_{3}$ pulses. The growth temperature was $320^{\circ} \mathrm{C}$. The growth rate was obtained based on the fitting outcome of XRR.

no physiosorbed In-species. According to our analysis [Figs. 4(d) and 4(e)], the averaged diameter of InN crystal grains is $9 \mathrm{~nm}$. This result is comparable to the value of $\mathrm{InN}$ grown by ALD using $\mathrm{N}_{2}$ plasma on the GaN surface as reported by Woodward et al. ${ }^{41}$ A finite inter distance (smaller than $7 \mathrm{~nm}$ ) between particles together with high particle density of $7.5 \times 10^{11} \mathrm{~cm}^{-2}$ indicates that the InN crystal grains are homogeneously distributed on the surface [Fig. 4(c)].

To better illustrate this coupled gas phase-surface dynamics in our ALD process, we utilized CFD modeling of the gas exchange in the reactor chamber. Figure 6 shows how the concentration of In species in the gas phase changes near the surface during the TMI pulse and the following $\mathrm{N}_{2}$ purge. With a purge time of $0.1 \mathrm{~s}$, the concentration of In species near the surface is only reduced slightly, while a $2 \mathrm{~s}$ purge time afford a significant but not complete removal of In species on the surface and in the chamber. A $2 \mathrm{~s}$ purge reduces the concentration to approximately one-eighth of the concentration just after the TMI pulse. This result coincides with the reduction in particle density observed between 0.1 and $2 \mathrm{~s}$ purge [Figs. 4(b) and 4(c)]. A purge time of $8 \mathrm{~s}$ and longer afforded a surface free from In species except those chemisorbed on the surface. It should be noted that the estimated necessary purge time is heavily dependent on the specific reactor design and carrier gas mass flow rate.

With increasing temperature, the degree of TMI decomposition increases and monomethyl indium (MMI) can form. ${ }^{43}$ MMI can undergo polymerization, forming poly-MMI, which has very low volatility. ${ }^{39}$ The formation of poly-MMI on the surface is not a self-limiting reaction and, thus, can continuously absorb In-species on to the surface as long as their concentration permits. Any formation of poly-MMI on the surface in an ALD process will, therefore, lead to formation of large crystal grains or droplets. At $450{ }^{\circ} \mathrm{C}$, the degree of TMI pyrolysis is even higher and the last $\mathrm{In}-\mathrm{CH}_{3}$ 


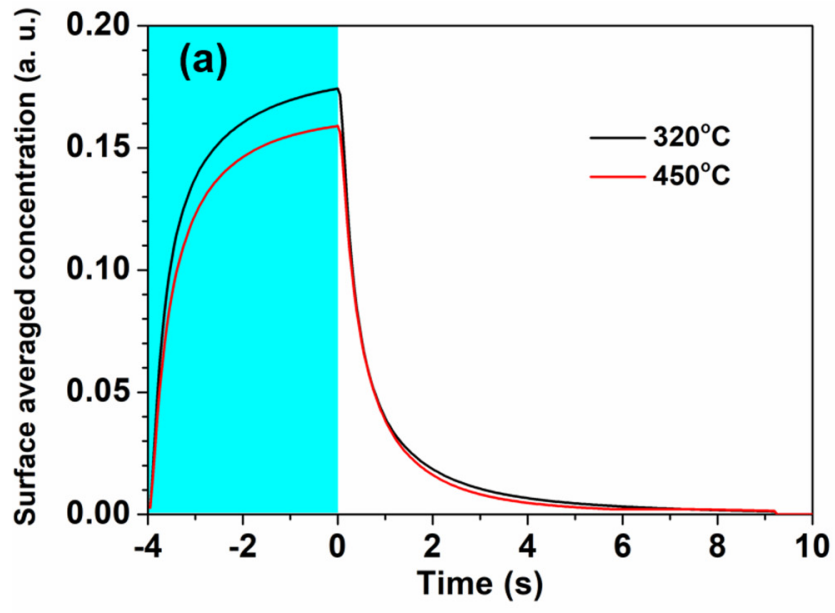

(b)
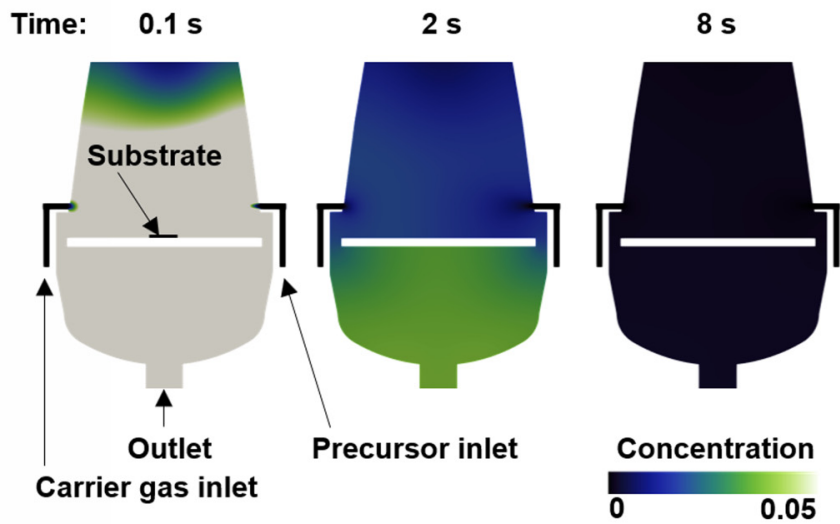

FIG. 6. Computational results of TMI concentration before and after the purge started in our growth process. (a) Average concentration over the substrate. The time between -4 and 0 represents the $4 \mathrm{~s}$ TMl pulse as indicated by blue shading. The time starting from 0 and afterward refers to the purge step. At $2 \mathrm{~s}$, there is a nonnegligible fraction of TMl left, whereas the gas above the substrate is effectively exchanged after $8 \mathrm{~s}$. This is visualized in (b), which shows residual TMI concentration over a cross section of the reactor chamber for different purge times. Note also that the flow field (and hence the required purge time) was relatively unaffected by temperature.

bond in MMI can break. This results in elemental In as reported by Jacko and Price ${ }^{43}$ and evidenced in our XRD of films deposited at $450{ }^{\circ} \mathrm{C}$ by ALD [Fig. 2(a)]. The reductive environment of the $\mathrm{NH}_{3}$ plasma makes the formation of $\mathrm{InN}$ not favored for elemental, zero valent, In as an oxidation to In(III) is needed for formation of InN. Elemental In, on the other hand, can be easily oxidized upon exposure to both residual oxygen in the chamber and ambient after deposition, resulting in the observation of $\operatorname{In}_{2} \mathrm{O}_{3}$ in our XRD [Fig. 2(a)].

\section{CONCLUSION}

We show that a time-resolved CVD approach by plasma ALD affords InN films with superior morphology and crystalline quality compared to a conventional, continuous CVD approach by standard thermal metalorganic CVD. We show that the key difference between the processes is not only the plasma activation of the ammonia but also the time-resolved precursor supply and how this is used to control the dynamics of the deposition chemistry. InN with smooth morphology can be obtained by the plasma ALD approach at $320^{\circ} \mathrm{C}$, provided that adequate time is given between the In- and N-precursors, presumably to allow physisorbed surface species to either chemisorb or desorb. We suggest that the detailed surface dynamics of In species is studied in detail by modeling to provide more insights. This study and previous findings in the literature demonstrate the importance of using a time-resolved precursor supply in CVD of InN in which the purge time plays an important role. It should also be noted that the best results in this study are outside the window where the deposition per ALD cycle is constant in temperature. Such observation suggests that a true, self-limiting ALD behavior is not the most critical factor but rather the dynamic precursor supply. Meanwhile, the experimentally optimal purge time and precursor pulse time should vary from reactor to reactor based on their geometry and volume.

\section{SUPPLEMENTARY MATERIAL}

See the supplementary material for full details on the XRR measurements and the CFD modeling.

\section{ACKNOWLEDGMENTS}

This work was financially supported by the Swedish Foundation for Strategic Research through the project "Time-resolved low temperature CVD for III-nitrides" (No. SSF-RMA 15-0018) and by the Knut and Alice Wallenberg Foundation through the project "Bridging the THz gap" (No. KAW 2013.0049). P.D. acknowledges the Carl Trygger Foundation for a postdoctoral scholarship at Linköping University. The centre in nano science and technology (CeNano) at Linköping University is acknowledged. The computations were enabled by resources provided by the Swedish National Infrastructure for Computing (SNIC) at National Supercomputer Center (NSC), partially funded by the Swedish Research Council through Grant Agreement No. 2018-05973.

\section{AUTHOR DECLARATIONS}

\section{Conflicts of Interest}

The authors have no conflicts to disclose.

\section{Author Contributions}

C.-W.H and P.D. contributed equally to this work. 


\section{DATA AVAILABILITY}

The data that support the findings of this study are available from the corresponding author upon reasonable request.

\section{REFERENCES}

${ }^{1}$ J. Wu, W. Walukiewicz, K. M. Yu, J. W. Ager, E. E. Haller, H. Lu, W. J. Schaff, Y. Saito, and Y. Nanishi, Appl. Phys. Lett. 80, 3967 (2002).

${ }^{2}$ V. M. Polyakov and F. Schwierz, Appl. Phys. Lett. 88, 032101 (2006).

${ }^{3}$ H. Liu, X. Wang, Z. Chen, X. Zheng, P. Wang, B. Sheng, T. Wang, X. Rong, M. Li, J. Zhang, X. Yang, F. Xu, W. Ge, and B. Shen, Appl. Phys. Lett. 112, $162102(2018)$.

${ }^{4} \mathrm{X}$. Li and X. Liu, Nanoscale 9, 7320 (2017).

${ }^{5}$ A. Yamamoto, M. R. Islam, T. T. Kang, and A. Hashimoto, Phys. Status Solidi C 7, 1309 (2010).

${ }^{6}$ K. S. Lye, A. Kobayashi, K. Ueno, J. Ohta, and H. Fujioka, Appl. Phys. Lett. 109, 032106 (2016).

7J. Kuzmik and A. Georgakilas, IEEE Trans. Electron Devices 58, 720 (2011).

${ }^{8}$ S. V. Ivanov, T. V. Shubina, T. A. Komissarova, and V. N. Jmerik, J. Cryst. Growth 403, 83 (2014).

9. B. MacChesney, P. M. Bridenbaugh, and P. B. O’Connor, Mater. Res. Bull. 5, 783 (1970).

${ }^{10}$ N. Dietz, M. Straßburg, and V. Woods, J. Vac. Sci. Technol. A 23, 1221 (2005).

"'M. Alevli, G. Durkaya, A. Weerasekara, A. G. U. Perera, N. Dietz, W. Fenwick, V. Woods, and I. Ferguson, Appl. Phys. Lett. 89, 112119 (2006).

${ }^{12}$ K. Rönnby, H. Pedersen, and L. Ojamäe, J. Vac. Sci. Technol. A 38, 050402 (2020).

${ }^{13}$ S. Ruffenach, M. Moret, O. Briot, and B. Gil, Phys. Status Solidi A 207, 9 (2010).

${ }^{14}$ S. Ruffenach, M. Moret, O. Briot, B. Gil, C. Giesen, M. Heuken, S. Rushworth, T. Leese, and M. Succi, J. Cryst. Growth 311, 2791 (2009).

${ }^{15} \mathrm{H}$. Lu, W. J. Schaff, J. Hwang, H. Wu, W. Yeo, A. Pharkya, and L. F. Eastman, Appl. Phys. Lett. 77, 2548 (2000).

${ }^{16}$ T. Ive, O. Brandt, M. Ramsteiner, M. Giehler, H. Kostial, and K. H. Ploog, Appl. Phys. Lett. 84, 1671 (2004).

${ }^{17}$ P. Jantawongrit, S. Sanorpim, H. Yaguchi, M. Orihara, and P. Limsuwan, J. Semicond. 36, 083002 (2015).

${ }^{18}$ M. Amirhoseiny, Z. Hassan, S. S. Ng, and G. Alahyarizadeh, Surf. Rev. Lett. 20, 1350008 (2013).

${ }^{19}$ M. Sato, Jpn. J. Appl. Phys., Part 2 36, L595 (1997).

${ }^{20}$ N. E. Richey, C. De Paula, and S. F. Bent, J. Chem. Phys. 152, 040902 (2020).

${ }^{21}$ N. Nepal, N. A. Mahadik, L. O. Nyakiti, S. B. Qadri, M. J. Mehl, J. K. Hite, and C. R. Eddy, Cryst. Growth Des. 13, 1485 (2013).

${ }^{22}$ A. Haider, S. Kizir, and N. Biyikli, AIP Adv. 6, 045203 (2016).
${ }^{23}$ P. Deminskyi, P. Rouf, I. G. Ivanov, and H. Pedersen, J. Vac. Sci. Technol. A 37, 020926 (2019).

${ }^{24}$ P. Rouf, N. J. O’Brien, K. Rönnby, R. Samii, I. G. Ivanov, L. Ojamäe, and H. Pedersen, J. Phys. Chem. C 123, 25691 (2019).

${ }^{25}$ N. J. O'Brien, P. Rouf, R. Samii, K. Rönnby, S. C. Buttera, C. W. Hsu, I. G. Ivanov, V. Kessler, L. Ojamäe, and H. Pedersen, Chem. Mater. 32, 4481 (2020).

${ }^{26}$ C.-W. Hsu, P. Deminskyi, I. Martinovic, I. Ivanov, J. Palisaitis, and H. Pedersen, Appl. Phys. Lett. 117, 093101 (2020).

${ }^{27}$ A. G. Bhuiyan, A. Hashimoto, and A. Yamamoto, J. Appl. Phys. 94, 2779 (2003).

${ }^{28}$ A. Blackman and L. Gahan, in Aylward Findlay's SI Chemical Data, edited by A. Blackman and L. Gahan (John Wiley \& Sons Australia Ltd., 2014), Chap. 17.

${ }^{29}$ A. Sungthong, S. Porntheeraphat, A. Poyai, and J. Nukeaw, Appl. Surf. Sci. 254, 7950 (2008)

${ }^{30}$ S. C. Cruz, S. Keller, T. E. Mates, U. K. Mishra, and S. P. DenBaars, J. Cryst. Growth 311, 3817 (2009).

${ }^{31}$ Z. Ahmad, G. B. Cross, M. Vernon, D. Gebregiorgis, D. Deocampo, and A. Kozhanov, Appl. Phys. Lett. 115, 223101 (2019).

${ }^{32}$ P. P. T. Chen, K. S. A. Butcher, M. Wintrebert-Fouquet, R. Wuhrer, M. R. Phillips, K. E. Prince, H. Timmers, S. K. Shrestha, and B. F. Usher, J. Cryst. Growth 288, 241 (2006).

${ }^{33}$ A. Kakanakova-Georgieva, G. K. Gueorguiev, S. Stafström, L. Hultman, and E. Janzén, Chem. Phys. Lett. 431, 346 (2006).

${ }^{34} \mathrm{M}$. C. Johnson, S. L. Konsek, A. Zettl, and E. D. Bourret-Courchesne, J. Cryst. Growth 272, 400 (2004).

${ }^{35}$ J. Mickevičius, D. Dobrovolskas, T. Steponavičius, T. Malinauskas, M. Kolenda, A. Kadys, and G. Tamulaitis, Appl. Surf. Sci. 427, 1027 (2018).

${ }^{36}$ R. S. Q. Fareed, R. Jain, R. Gaska, M. S. Shur, J. Wu, W. Walukiewicz, and M. A. Khan, Appl. Phys. Lett. 84, 1892 (2004).

${ }^{37}$ H. Pedersen, Chem. Mater. 28, 691 (2016).

${ }^{38}$ Y. An, Y. He, H. Wei, S. Liu, M. Li, Y. Song, P. Qiu, A. Rehman, X. Zheng, and M. Peng, Results Phys. 12, 804 (2019).

${ }^{39}$ N. I. Buchan, C. A. Larsen, and G. B. Stringfellow, J. Cryst. Growth 92, 591 (1988).

${ }^{40} \mathrm{~K}$. Ronnby, "A computational study on indium nitride ALD precursors and surface chemical reactions," MSc thesis, Linköping University, Sweden (2018), see http://liu.diva-portal.org/smash/record.jff?pid=diva2\%3A1177404\&dswid=1700.

${ }^{41}$ J. M. Woodward, S. G. Rosenberg, A. C. Kozen, N. Nepal, S. D. Johnson, C. Wagenbach, A. H. Rowley, Z. R. Robinson, H. Joress, K. F. Ludwig, and C. R. Eddy, J. Vac. Sci. Technol. A 37, 030901 (2019).

${ }^{42}$ T. Muneshwar and K. Cadien, J. Appl. Phys. 124, 095302 (2018).

${ }^{43}$ M. G. Jacko and S. J. W. Price, Can. J. Chem. 42, 1198 (1964). 